\title{
Patient satisfaction on colposcopy services
}

\begin{abstract}
Objective: To know the patient satisfaction on colposcopy services in Royal Bolton Hospital

Methods: Questionnaire was given to patients in clinic to be filled after the colposcopy/ procedure. Total 65 questionnaires were given and 50 were received. A self-devised questionnaire was used.

Results: Patients were very satisfied with the explanation at each step of colposcopy and felt that overall communication was excellent. All patients except one were very happy to recommend colposcopy to their friends.

Discussion \& Conclusion: This suggests that the centre $(\mathrm{RBH})$ is doing well. The primary health services could be trained at the RBH. The study performed is a very small study but touches a very important aspect of women's health and corroborates with other studies.
\end{abstract}

Volume 9 Issue I - 2018

\author{
Uma Pandey \\ Department of Obstetrics \& Gynaecology, Banaras Hindu \\ University, India
}

\begin{abstract}
Correspondence: Uma Pandey, Associate Professor, Department of Obstetrics \& Gynaecology, Institute of Medical Sciences, Banaras Hindu University, 6 FF Kabir Colony, Varanasi, Uttar Pradesh, India, 221005, Tel 00919793094060, Email uma.pandey2006@yahoo.com
\end{abstract}

Received: September 15, 2017| Published: January II, 2018

Keywords: Colposcopy, Cervical smears abnormality, Patient satisfaction

\section{Objective}

To know the patient satisfaction on colposcopy services in Royal Bolton Hospital. ${ }^{1,2}$

\section{Methods}

Audit was carried out in the obstetrics and gynaecology of Royal Bolton hospital by Uma Pandey SSHO obstetrics and gynaecology. Questionnaire was given to patients in clinic to be filled after the colposcopy/procedure. Total 65 questionnaires were given and 50 were received. A self-devised questionnaire was used.

\section{Results}

$58 \%$ of patients had waiting time between $4-8$ weeks (Figure 1). 40 patients felt that waiting time was appropriate. Majority of patients were not happy about the explanation given to them before colposcopy (Figure 2).

\section{Waiting Time}

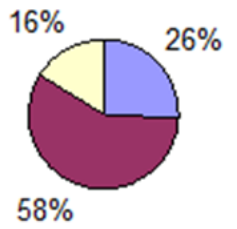

口less than 4

$\square$ between 4 \& 8

$\square$ more than 8

$58 \%$

Figure I Waiting time between 4-8 weeks.

$40 \%$ of patients had colposcopy within 15 minutes. $36 \%$ had colposcopy between $15-30$ minutes while $21 \%$ had to wait for more than 30 minutes. Only one patient had to wait for more than 60 minutes. Only 5 patients out of 38 complained that operation performed was uncomfortable (Figure 3).

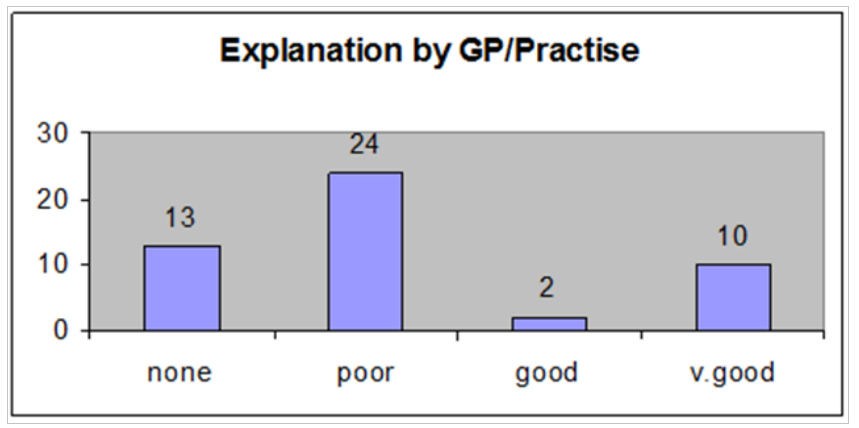

Figure 2 Explanation by GP/Practise.

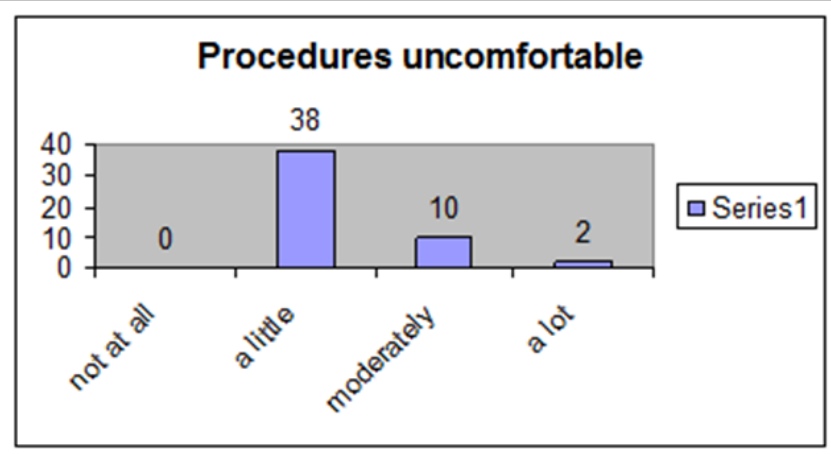

Figure 3 Uncomfortable procedures.

Patients were very satisfied with the explanation at each step of colposcopy and felt that overall communication was excellent. All patients except one were very happy to recommend colposcopy to their friends.

\section{Discussion}

$58 \%$ of patients had waiting time between 4-8 weeks and majority of patients (40/50) felt that waiting time was appropriate. $40 \%$ of patients had colposcopy within 15 minutes. Patients were very satisfied with the explanation at each step of colposcopy and felt that overall 
communication was excellent. Patients were happy to recommend the colposcopy clinic at RBH to others.

$26.5 \%$ patients were satisfied with the explanation give by GP regarding smear abnormality and need for colposcopy and procedure. $24.48 \%$ complained the procedure was uncomfortable.

This suggests that the centre (RBH) is doing well. The primary health services could be trained at the RBH. The study performed is a very small study but touches a very important aspect of women's health and corroborates with other studies. ${ }^{3-5}$

\section{Acknowledgements}

None.

\section{Conflicts of Interest}

None.

\section{References}

1. Sanders G, Craddock C, Wagstaff I Factors influencing default at a hospital colposcopy clinic. Qual Health Care. 1992; 1(4):236-240.

2. Patterson T, Roworth M, Hill M An investigation into the default rate at the Fife colposcopy clinic: implications for target setting. J Public Health Med. 1995; 17(1):65-69.

3. Adewuyi SA, Shittu SO, Rafindadi AH Sociodemographic and clinicopathologic characterization of cervical cancers in northern Nigeria. Eur J Gynaecol Onco. 2008;1 29(1):61-64.

4. Fung Kee Fung M, Howlett RI, Oliver TK, Murphy J, Elit L, et al. The optimum organization for the delivery of colposcopy service in Ontario: a systematic review. J Low Genit Tract Dis. 2010; 14(1):11-21.

5. Browman GP, Levine MN, Mohide EA, Hayward RS, Pritchard KI, et al. The practice guidelines development cycle: a conceptual tool for practice guidelines development and implementation. J Clin Oncol. 1995; 13(2): 502-512. 